\title{
Uncertainty over MAiD likely to continue
}

A conference aiming to provide clarity to would-be practitioners of medical assistance in dying (MAiD) raised many more questions than it answered. In the end, it may take a decade to achieve clarity.

Dr. Jeffrey Turnbull, chief of staff at The Ottawa Hospital where 1200 physicians work, has already changed his hospital's policy five times since the MAiD law came into effect in June 2017. "There are enormous logistical issues as we try to deliver," said Turnbull at the Ottawa Conference on MAiD on Oct. 15. He says staff are asking questions about determining qualification and competence, the rules for conscientious objectors and timely referrals, and much more.

Many of these issues were addressed during the conference, which was hosted by the University Ottawa Centre for Health Law, Policy and Ethics. But few conclusive answers were forthcoming.

It may take a decade or more to sort out all the details, said retired Madam Justice Lynn Smith, who ruled on the pivotal Carter case in the British Columbia Supreme Court.

The Carter case went to the Supreme Court of Canada, which ruled in November 2015 to allow MAiD. The new federal law came into effect on June 17. It removed prohibitions against assisted dying and established national guidelines while sparking uncertainty among health professionals on how exactly to proceed. The law is already facing a court challenge by Julia Lamb and the BC Civil Liberties Association.

"We've seen in Carter, litigation followed by legislation followed by further litigation and there'll no doubt be more legislation and maybe even more and more litigation," said Smith. "In a decade or so, we'll look back and see debates about whether all of this dialogue has resulted in the

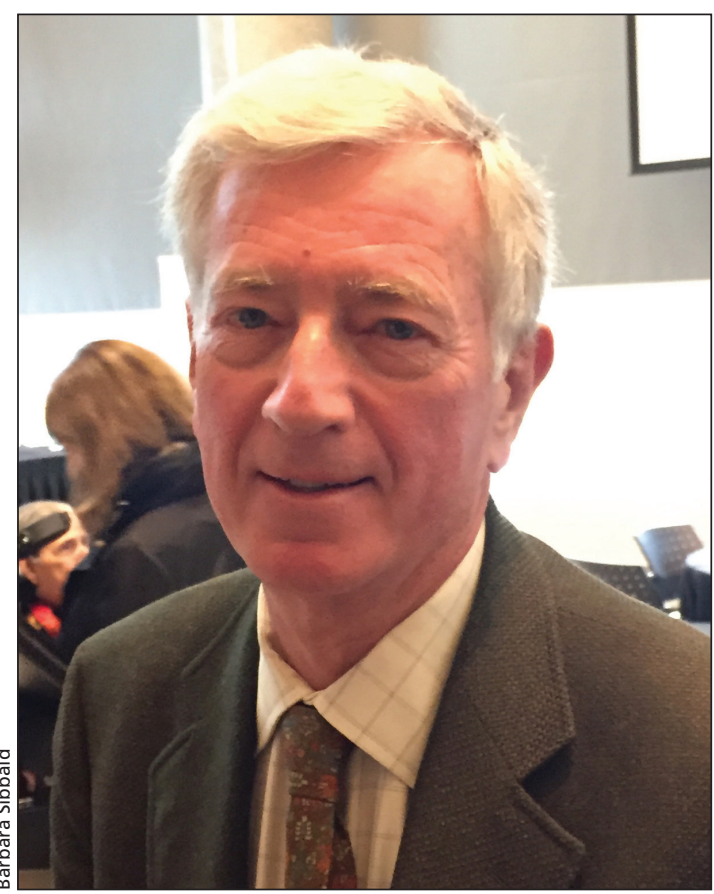

Hope for clarity on medical assistance in dying may, in the short term, be in vain, said Dr. Harvey Schipper.

best possible laws and practices for Canadians."

The concepts in the law leave a lot of space for the people providing MAiD to define how it will be provided, said Daniel Boivin, general counsel to the Canadian Medical Protective Association, the 95 000-member, not-forprofit medical mutual defence organization. This is probably a good thing in the long term, "but it's a little bit unnerving for people asked in these early days to provide the services," he added.

"Liability is vastly reduced with the federal legislation, but it's not eliminated," Boivin said. Providing MAiD outside the legal framework could result in criminal prosecution, so it's "vital to adhere to every step as mandated by the law, colleges and hospital guidelines," he added. Civil prosecution is more likely, including claims of inadequate or compromised consent, and negligence in provision of services. Boivin urged nurse practitioners and physicians to contact their legal advisors when asked to provide MAiD.

"It's difficult to imagine many cases arising" if protocol is followed, said Lorian Hardcastle, associate director of the Centre for Health Law, Policy and Ethics. "I'm not saying there's no concern regarding liability, but our guidance about MAiD is not going to come from the courts."

It's essential we gather information so that we have a body of knowledge with which to move forward, Dr. Harvey Schipper, a professor of medicine at the University of Toronto told conference attendees. We need to learn broadly and deeply, the "real clinical stories behind MAiD. The more we make MAiD unnecessary because we improve the lives of our patients, the better off we are."

Meanwhile court challenges continue to emerge, including one over the College of Physicians and Surgeons of Ontario's requirement for conscientious objectors to refer patients. The Coalition for HealthCARE and Conscience, comprised of physicians and 100 health care facilities across Canada, says that such referrals are tantamount to condoning MAiD.

But Carolyn McLeod, a professor of philosophy at Western University in London, Ont., argued that the fiduciary nature of the physician-patient relationship requires physicians to act in their patient's best interest. "The central duty of a fiduciary is one of loyalty, so that's a duty to essentially place the beneficiaries' interest ahead of your interest," said McLeod. The most loyal thing to do in these situations is to refer to someone else, she concluded.

Some Catholic hospitals are also seeking to be exempt from providing MAiD. Richard Moon, an expert on Constitutional law who teaches at Windsor University, argued that only institutions formed for religious 
purposes and acting in pursuit of that purpose can claim exclusion under Section 2a of the Charter of Human Rights and Freedoms.

Still, it's not clear whether Catholic hospitals will be required to perform this service, he added. If provinces excuse them, they will be obliged to ensure these services remain accessible, he said.

Consent to MAiD in the context of underage patients or those suffering from mental illness or cognitive impairment, may be among those issues addressed by the federal government when it begins a review of the legislation in December.

Meanwhile, patients with unbearable mental suffering whose death is not foreseeable have been denied MAiD.

"There's no reason why in fact the same rules ... need to apply in the case of nonterminal patients. There could be separate rules," said Jennifer Chandler, the Bertram Loeb Research Chair at the University of Ottawa's Faculty of Law.

She suggested a compromise might look at what is reasonable under the circumstances. Meanwhile, "we need an idea of how to handle such cases."
The same view was expressed for patients under the age of 18 who request MAiD. Currently, the law only allows people over 18 to consent to MAiD. But capable minors in Ontario are already making decisions - such as refusal of treatment - that could lead to their death, said Randi Zlotnik Shaul, director of bioethics at The Hospital for Sick Children in Toronto.

If MAiD is recognizing as a possibility for capable adults with intractable suffering, how can clinicians deny such a benefit to similarly situated minors? she asked. Such consent would be founded in the values of what is in the best interest of the child and respect for their emerging autonomy. Clinicians have to be clear about rationale for restricting consent to people who are 18 and above, or not, said Zlotnik Shaul.

"The idea of waiting until 18 is ridiculous," added Dr. Gerrit Kimsma, a Dutch expert in MAiD who testified at the Carter case. He said that children as young as six or eight who have undergone multiple medical interventions can develop a maturity that is unusual for their age. Consent from such minors is sometimes permissible in the Netherlands.
Patients with cognitive impairment, such as those with Alzheimers, also present challenges. Some, whose death is not foreseeable, may want to provide advance directives about providing MAiD. But the Canadian law stipulates that consent must be given immediately prior to MAiD, something these patients may no longer be capable of providing.

In the Netherlands, MAiD is provided to patients with dementia, but consent is necessary. "If the person doesn't know what's happening then it becomes like an act of veterinarian medicine and that's not humane," said Kimsma.

Our legal ability to deal with consent needs to evolve, concluded Colleen Flood, director of the Ottawa Centre for Health Law, Policy and Ethics.

The Ottawa Conference on MAiD was cosponsored by the University Ottawa, the Canadian Institutes of Health Research, the Canadian Medical Association, the Canadian Nurses Association and the Borden Ladner Gervais law firm. - Barbara Sibbald, CMAJ

CMAJ 2016. DOI:10.1503/cmaj.109-5343 